\title{
Investigating overheating by measurement and simulation in classrooms
}

\author{
Matthias Pazold ${ }^{1}$, and Matthias Winkler $^{1}$ and Florian Antretter ${ }^{1}$ \\ ${ }^{1}$ Fraunhofer Institute for Building Physics IBP, 83626 Valley, Germany
}

\begin{abstract}
New two-story wood-construction classrooms where added to an existing heavy-weight construction school building in the year 2006. The glass façade of some classrooms is south oriented. The building design meets the local thermal protection requirement of 2006, but the indoor temperature rises above thermal comfort conditions in the classrooms. As usual in Germany, no active cooling device is and shall be used. Measurements during holidays with close to none internal loads in addition to measurements during regular school occupancy documented the overheating. The measurement results were used to verify a baseline hygrothermal building simulation model that represents the status quo. Various passive measures with regards to construction, design and operation to improve the thermal comfort were assessed. Among them are ventilation strategies and solar protection foil on the glass façade. Furthermore, the already installed temporary sunscreen devices and mechanical night ventilation system coupled to mechanically openable skylights above the classroom doors and within the gravel covered flat roof were investigated with different operating strategies. This paper presents the required steps to improve the simulation model with the measured data in an iterative process. Measures to improve building performance, achieve thermal comfort, and protect overheating are identified.
\end{abstract}

\section{Introduction}

A light-weight construction building extension to a German school, which was added in 2008, shows an acute summertime overheating problem of classrooms. In the past, individual measures have already been implemented to reduce this problem, but they have not been able to reduce the overheating. This paper presents a room climate evaluation by means of dynamic building simulation, validated with measured data, in order to determine the main influencing parameters and, based on this, to develop measures to reduce the overheating problem.

The hygrothermal building simulation enables a dynamic indoor climate evaluation of the building and its individual zones, taking into account the overall system consisting of its structural and technical components. This enables different planning variants to be compared with each other and their effects on the thermal and hygric room climate to be evaluated in order to optimise the planning and operation of the building. This includes, for example, the evaluation of shading, ventilation and air-conditioning strategies or the consideration of different user behaviour. Since the dynamic simulation depicts a typical year, the statements on the expected indoor climate include both normal and extreme climate conditions.

The investigations are carried out with the aid of the method for calculating the coupled heat and moisture transport in WUFI ${ }^{\circledR}$ building components, which was developed at the Fraunhofer Institute for Building Physics IBP and has been validated many times experimentally [1]. The program WUFI@ fully complies with the requirements of the new European standard DIN EN 15026 for hygrothermal simulation. The building simulation model WUFI ${ }^{\circledR}$ Plus is used, which is also validated [2] and supports a multi-zone hygrothermal simulation [3].

For the technical simulation of the extension, the building is modelled as a multi-zone simulation model. Each of the mainly used rooms (classrooms, seminar room, multi-purpose room) is considered as an individual zone in the model. Thus, the most critical rooms for overheating and the determining influencing factors can be reproduced and evaluated. Measures to reduce summer overheating and its influence on the remaining parts of the building can be taken into account and evaluations of the energy demand also include the entire extension.

\section{Measurements}

Measurements of the indoor climate in four of the most critical rooms of the school were carried out. The measurement data obtained were processed and used for the calibration and validation of the simulation model. For the measurements, a system was used which continuously records the indoor air temperature as well as the prevailing outdoor climate (temperature, humidity, solar radiation). The measured data were stored centrally

\footnotetext{
* Corresponding author: matthias.pazold@ibp.fraunhofer.de
} 
and evaluated after the measurement campaign was finished. Temperature was measured with Pt100 sensors class A with an accuracy of $+/-0.1 \mathrm{~K}$, relative humidity was measured with capacitance sensors with an accuracy of $+/-1.5 \%$ r.H. at $23^{\circ} \mathrm{C}$. The required measurement sensors were pre-calibrated by the Fraunhofer Institute for Building Physics IBP. The sensors were installed in the middle of the classrooms at a height of $3 \mathrm{~m}$. In addition, a temperature sensor was installed in two rooms at a height of $1.70 \mathrm{~m}$. In one room the relative humidity was measured at a height of $3 \mathrm{~m}$. In addition, the temperature in the corridor and staircase was measured. Within the scope of the metrological investigation, a weather station was also set up to record the outdoor climate.

During the measurement period, the teachers in the 4 classrooms in which the measurement equipment was located were asked to record the number of people present, the status of the windows (open, closed) and the status of the sun protection for one week. The obtained information is used to generate typical user profiles of the classrooms for the simulation. The obtained information is very diffuse. In the following, the user profile used for the simulation is not defined exactly following the protocol but derived from it in a simplified way.

\section{Simulation model}

The simulations are used to investigate two climatic situations: First, the simulation model is examined with measured outdoor climate conditions for the period with indoor climate measurement data. This simulation is used to validate the building model. A limited period of time was measured, the measured data is therefore not sufficient for the subsequent investigations of the overheating problem. For the reference case (actual state) as well as for the consideration of the variants, a year-round outdoor climate data set representative for the location is used: a test reference year [4] corresponding to the location, which is developed for the simulation of heating and ventilation systems and the thermal behaviour of buildings.

\subsection{Weather data}

The measured weather data were compared with weather stations of the German Weather Service (DWD) (solar radiation: station no. 05404, Weihenstephan-Dürnast [5] and air temperature and humidity: station no. 13710, Landshut-Reithof [6] and checked for plausibility. Outside the measuring period from 28.8.2018 to 3.11.2018 the measuring data were completed with the mentioned sources of the German Weather Service for the course of the year. Due to a sensor failure in the weather station, the outdoor air temperature could not be recorded all the time during the measurements. The missing data were also supplemented from the nearest DWD weather station. The outdoor climate data set for the simulation to validate the building model contains the climate data necessary for the building simulation:
Air temperature, air humidity, global solar irradiance, diffuse solar irradiance, as well as irradiance of atmospheric heat radiation in relation to the horizontal surface (counter-radiation).

The heat transfer via the ground is calculated based on DIN EN ISO 13370 [7] and taken into account in the simulation. A category II soil (sand or gravel) is used as the type of soil is unknown.

For the school site, the representative test reference year (TRY) climate data set (test reference year data set 2017 BBSR) [4] is used as the outdoor climate for the parametric investigations. The cyclical TRY data sets for a complete year have the purpose of providing climatological boundary conditions for the simulation of heating and ventilation systems and the thermal behaviour of buildings. For the evaluation of the thermal indoor climate, the test reference year data sets are recommended according to DIN 15251:2012 [8].

\subsection{Shading}

Apart from possible self-shading due to the building geometry and window embrasure, the shading from the neighbouring buildings in the west is assumed. Further neighbouring buildings and topography of the terrain are not considered. The tree population in the north is regarded with and constant shading factor of 0,8 for the diffuse radiation. A reduction of the solar heat gains due to dirt or otherwise contaminated window panes is not assumed.

\subsection{Inner loads}

It is assumed that there is a partial difference in classroom occupancy of 20 to 30 people. During their presence Monday to Friday, from 8:00 to $16: 45$, the persons emit heat, humidity and $\mathrm{CO} 2$ in one room or classroom. A slight activity of seated persons is assumed. During breaks the number of persons is reduced to 5 to represent some fluctuations. There are no persons in the classroom during lunch break. The heat emission is based on DIN EN ISO 7730 [9] and is defined as $2 / 3$ convective and $1 / 3$ radiant heat emission in the zone. The humidity emission is based on VDI 2078 [10] and the CO2 emission on VDI 4300 [11]. Internal heat sources are estimated for the year 2018 on school days (Mon-Fri) taking into account holiday periods in Bavaria. No additional heat and humidity loads from electronic devices or plants are added to the model. The use of the classrooms was surveyed by means of a questionnaire. On this basis, usage profiles were drawn up for the individual classrooms. The profiles are intended to represent the usual use of the classrooms.

\subsection{HVAC system and passive cooling plan}

In the 6 classrooms on the south side, decentralised mechanical supply air fans with a maximum supply air volume flow of $750 \mathrm{~m}^{3} / \mathrm{h}$ are installed in the facade. In 
the period from May to the end of September from 22:00 to 7:00 o'clock a night ventilation program is active.

A room thermostat is installed in each of the 6 classrooms, on which the minimum room temperature is set. If the room temperature falls below the minimum temperature, the thermostat switches off the fan and closes the shutter of the fan. The setting knobs are dismantled by the caretaker after the proper setting (20 $21^{\circ} \mathrm{C}$ ), but according to information from the client, there is a certain potential for error here, as the students still manipulate the thermostats even without the setting knob.

In the simulation model, temperature-controlled fans were added in the 6 classrooms, which are provided with the maximum fan capacity in the mentioned period. If the indoor temperature is above the target temperature, $21^{\circ} \mathrm{C}$ is set here, the fans are active. If the temperature falls below the target temperature, the fans are also switched off in the simulation model. For the ventilation program, the skylight windows of all classrooms are brought into a hinged position, and the roof windows in the corridor on the upper floor and staircase are opened.

Beside the automatic setting of the roof windows they can also be operated manually, but this is not regarded in the simulation.

External blinds are available over the entire window area and are operated manually. Often these are only half closed. On activation the sun protection is taken into account starting at a solar radiation of more than 200 $\mathrm{W} / \mathrm{m}^{2}$ on a window surface. If activated, a reference value of the reduction factors according to DIN 4108-2 table 7 [12] of 0.25 , or 0.5 half closed, is applied for external blinds with rotatable slats in $45^{\circ}$ slat position.

The simulation model regard an ideal heating and within one variant a cooling system in the building. This type of building system simulation provides the demand to maintain the setpoint settings in full and without delay.

\subsection{Building dimensions}

The part of the building to be simulated is created as a three-dimensional building model according to the building owners's plans, see Figure 5. Classrooms, corridors on the ground and upper floors, staircase and ancillary rooms are individually modelled in a multizone model. The model of the building is shown in Fig. 1 and the cross-sections of ground level and first floor are shown in Fig. 2 and 3.

Outer building dimensions: length: $38.00 \mathrm{~m}$ width: $18,00 \mathrm{~m}$ height: $7,40 \mathrm{~m}$

Roof area: $\quad$ Flat roof $588 \mathrm{~m}^{2}$

Net area: $\quad 1,044 \mathrm{~m}^{2}$

Net volume: $\quad 3.287 \mathrm{~m}^{3}$

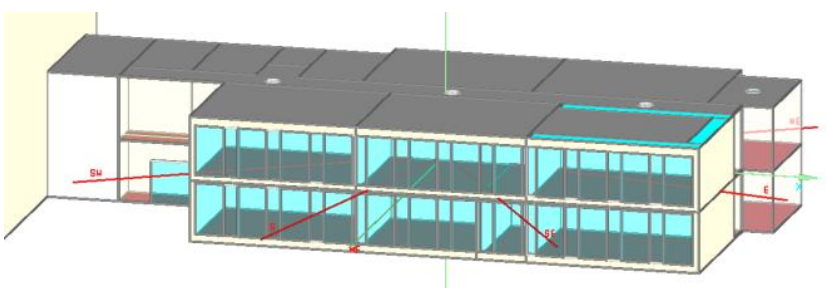

Fig. 1. Simulation model in WUFI ${ }^{\circledR}$ Plus.

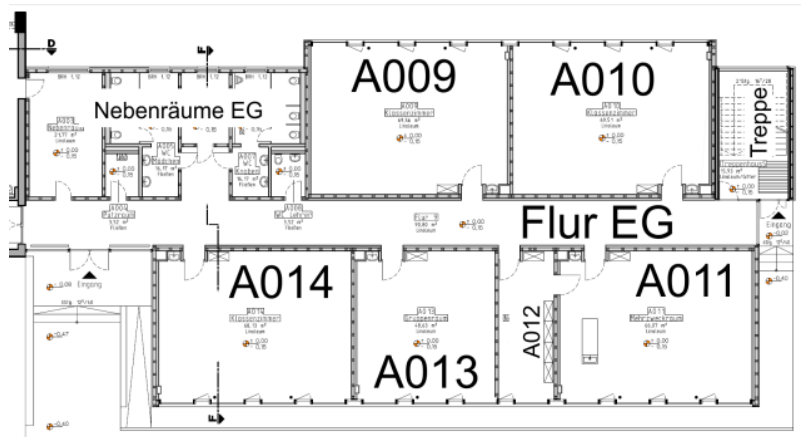

Fig. 2. Cross-Section of the ground level

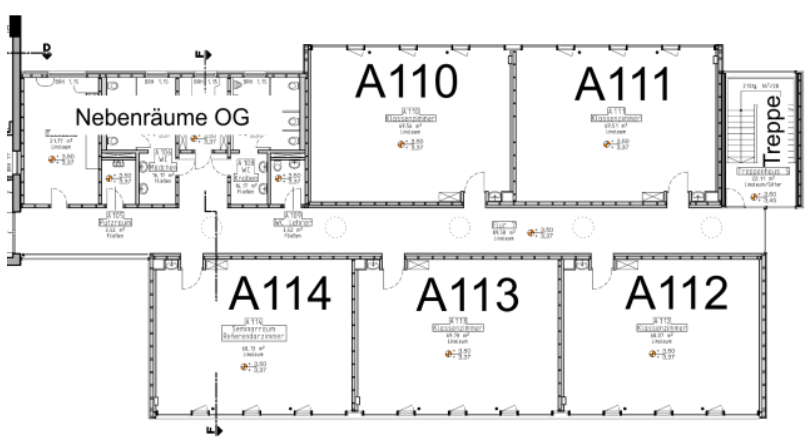

Fig. 3. Cross-Section of the $1^{\text {st }}$ floor

\subsection{Building components}

The building consists of light-weight exterior walls with $16 \mathrm{~cm}$ wood fibreboard insulation, interior walls consisting of gypsum boards and mineral wool insulation, an insulated concrete slab, an interior ceiling with CLT and gypsum fibreboard floor and a float roof with gravel on an EPS insulation on top of a CLT structural element. All components are modelled according to the specifications of the building owner. Suitable material parameters are taken from the WUFI ${ }^{\circledR}$ material database or adjusted according to provided material data.

The selected outdoor climate is applied to the outer surface of outdoor components. The simulated interior climate is applied to all interior component surfaces and thus to both sides of interior components, e.g. interior walls.

All components are modelled as one-dimensional homogeneous constructions. An ideal on-site execution is assumed. U-values and mass of the constructions per $\mathrm{m} 2$ area are shown in Table 1. 
Table 1. Building components and properties.

\begin{tabular}{|c|c|c|}
\hline Exterior wall & $\begin{array}{c}\text { U-Value } \\
{\left[\mathrm{W} / \mathrm{m}^{2} \mathrm{~K}\right]}\end{array}$ & $\begin{array}{c}\text { Mass } \\
{\left[\mathrm{kg} / \mathrm{m}^{2}\right]}\end{array}$ \\
\hline Interior wall & 0.157 & 69 \\
\hline Ground Floor & 0.341 & 830 \\
\hline $\begin{array}{c}\text { Interior } \\
\text { ceiling }\end{array}$ & 0.275 & 252 \\
\hline Flat roof & 0.142 & 273 \\
\hline $\begin{array}{c}\text { Windows } \\
\text { (main façade) }\end{array}$ & $\begin{array}{c}1.4 \\
\text { (g-Value 0.48) }\end{array}$ & \\
\hline
\end{tabular}

\section{Comparison Measurement -Simulation}

\subsection{Comparison of measured data and simulation}

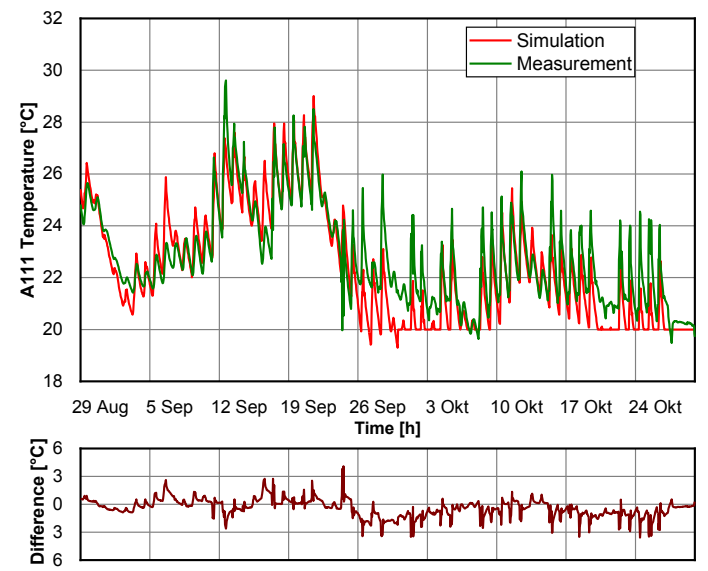

Fig. 4. Comparison of inner air temperature: measurement data - simulation result in classroom A111.

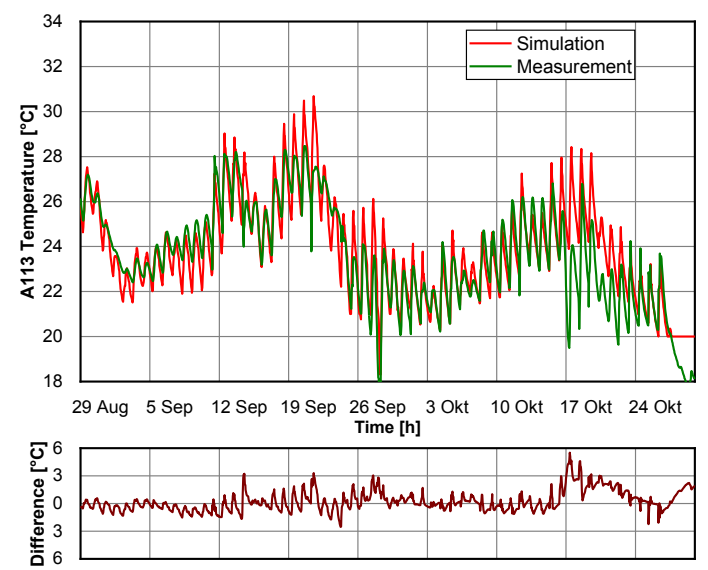

Fig. 5. Comparison of inner air temperature: measurement data - simulation result in classroom A113.
The simulation calculation shows approximately the course, amplitude and average value of the measured data. Comparison and deviation in the classrooms A 111 (north-oriented) and A 113 (south-oriented) are shown in Fig. 4 and Fig. 5.

\subsection{Learning from the measured data}

Comparing first simulation results with measured data does not fit very well at first. It was necessary to adjust some input data and assumed properties of the simulation model to improve or achieve consistency with the measured data.

A noticeable difference in classroom A 113 was a lowering of the room air temperature to about $18^{\circ} \mathrm{C}$ during the night from 27 to 28 September. However, the night ventilation program is limited to $21^{\circ} \mathrm{C}$. An increased, unrestricted natural air exchange rate was applied to this classroom during this night, like it can probably occur with windows are open. With this increased night air change, it was possible to reproduce the course of the measured data.

Another specification for the building system data was and mechanical supply air capacity of $750 \mathrm{~m}^{3} / \mathrm{h}$ during the night ventilation program. However, significant lower temperatures at night were observed within the first simulations, often fall to the set temperature of $21^{\circ} \mathrm{C}$, the border the fans turn off. The measured data doesn't represent that. Furthermore, the night ventilation program is active until 30 September. Later than that date, in late fall and winter, the night ventilation program is deactivated. During this time the simulation fit well with the measurement data. Following this, the mechanical night supply air flow rate was adjusted, to reproduce the measured air temperature with the simulation, assuming the fans didn't manage it to achieve the maximum volume flow rate.

\subsection{Measurement conclusion}

The measurements were helpful for testing the simulation model and assumptions of the boundary conditions could be confirmed or adjusted. The simulations show the temperature curves, amplitude and mean value of the temperatures. The minimum, maximum and mean values of the deviation between simulated indoor temperature and measured indoor temperature are summarized in Table 2 . The respective minimum and maximum values are shown. The large deviations in the extreme value are due to the real building operation (presence of persons, window opening times, open or closed interior doors) which were not available in enough detail for the entire measuring period. The average value per measuring point is below $1^{\circ} \mathrm{C}$. The mean value of the deviation across all measuring points is $-0.02^{\circ} \mathrm{C}$.

The simulation model is suitable for mapping the interior temperature of the classrooms in the extension of the school. 
Table 2. Comparison of results between measurement and simulation of different classrooms, corridor and staircase.

\begin{tabular}{|c|c|c|c|}
\hline \multirow{2}{*}{ Room } & \multicolumn{3}{|c|}{ Deviation [K] } \\
\cline { 2 - 4 } & Min-value & Max-value & Mean-value \\
\hline A111 & -3.51 & 4.88 & -0.03 \\
\hline A112 & -2.91 & 3.57 & -0.87 \\
\hline A113 & -3.13 & 5.48 & 0.38 \\
\hline A114 & -2.95 & 5.42 & 0.13 \\
\hline $\begin{array}{c}\text { Corridor 1st } \\
\text { floor }\end{array}$ & -1.66 & 4.43 & 0.42 \\
\hline staircase & -4.17 & 6.17 & -0.11 \\
\hline
\end{tabular}

\section{Simulation study}

\subsection{Reference simulation}

For the validation of the simulation model described in chapter 4 , a temporally limited outdoor climate data set matching the measurements was used. In order to obtain typical simulation results, a test reference year outdoor climate data set representative for the building site was used for the further investigations. Boundary conditions which were adjusted in the context of the comparison of measured data in chapter 4 are considered as described there. Different variants of the school building and its use are considered. At first a reference simulation is carried out which represents the current state of the building. Based on this reference model, variants are derived and compared to the reference model for evaluation.

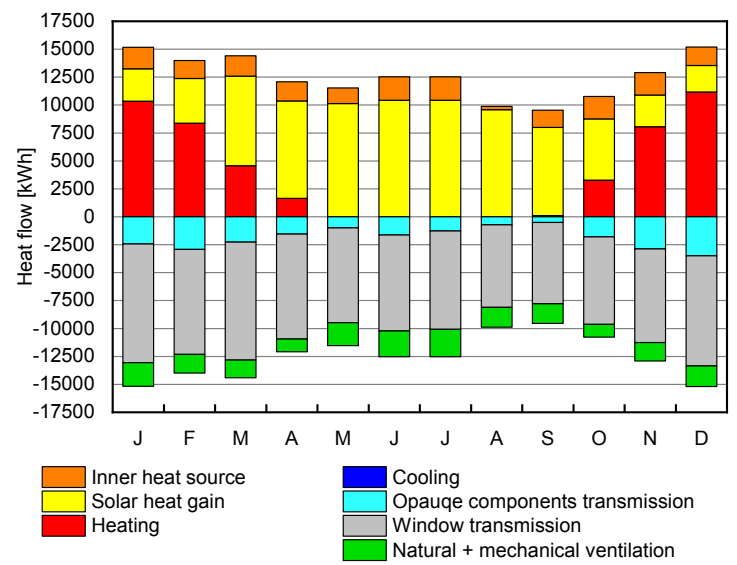

Fig. 7. Monthly totals of the heat flows of the reference simulation.

Fig. 7 shows the monthly totals of the heat flows in the entire annex (classrooms, including corridors, ancillary rooms and stairwell). These are totals without taking individual positive or negative heat flows into account. As an example: If 100 watts are emitted to the room via an opaque building component and (-)100 watts are simultaneously absorbed by the room via an opaque building component, this results in a contribution of 0 watts to the monthly total in Fig. 7.

The transmission through the opaque components is very low in monthly totals compared to the transmission through the transparent components. Even in the summer months, more heat is dissipated to the outside via transmission through opaque and transparent components as the average outdoor temperature is lower than the average indoor temperature, at least due to the overheating issue. The heat transport as a result of air exchange, also in total over each month from inside to outside, is very low compared to transmission. The dominant heat source in the summer months is the solar input via the transparent building components, still clearly above the internal heat sources (people present).

Fig. 8 shows the range of the recommended operative room temperature as area between the two solid lines. The specifications of the operative room temperature refer to the hourly mean values of the outside air temperature. For compliance with Class II, the class recommended for new and refurbished existing buildings according to DIN 15251:2012 [8], a degree hour criterion is used for the evaluation of the calculation results. Class II is considered to be still achieved if the deviation from the tolerance range for the operative room temperature is $2 \mathrm{~K}$ in less than $1 \%$ of the room's usage time. Smaller deviations are permitted over longer periods of time according to the degree hour criterion. [8]. For the degree-hour criterion, a permissible deviation of $29 \mathrm{~K} \mathrm{~h} / \mathrm{a}$ is calculated based on the assumed time-of-use of 1480 hours in the year.

In summer, only slightly above $20 \%$ of the time in which the classrooms are used, the simulated room temperature is withing the thermally comfortable room temperature. Measures to reduce the room temperature during the period of use are necessary.

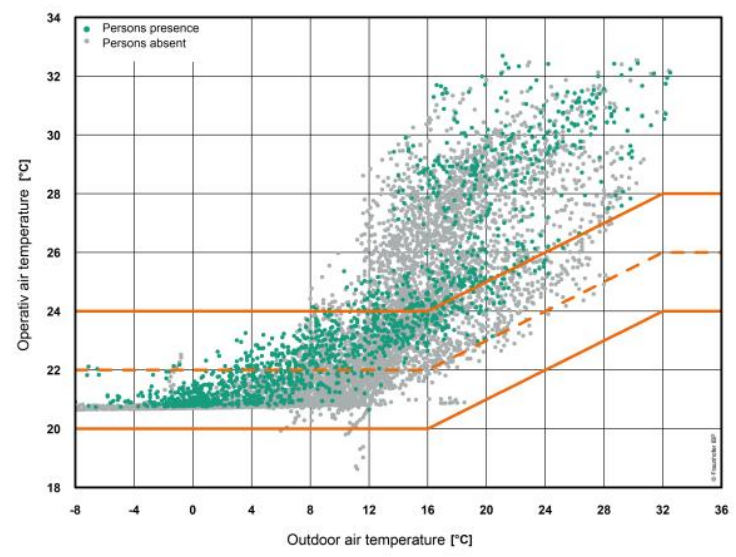

Fig. 8. Reference case classroom A113: Operating temperature based on outside air temperature Comfort range according to DIN 15251:2012 [8] National Annex NA.3 Thermal room climate 


\subsection{Variations}

\subsubsection{Active cooling}

With this variant, the indoor climate is considered with active sensitive cooling. In addition to the room climate, the hourly ideal cooling capacity required to maintain a target room air temperature is calculated in this case. Ideal cooling capacity means the cooling unit itself and the cooling distribution is not shown in the simulation. The cooling is switched on during the night ventilation program, from 1.5. to 30.9.. In this variant, the set target room air temperature is set $1.5 \mathrm{~K}$ above the comfort room air temperature according to DIN EN 15251 [8] National Appendix NA.3.2.2 and should therefore be within the tolerance range $(+/-2 \mathrm{~K})$ but at the same time save cooling energy.

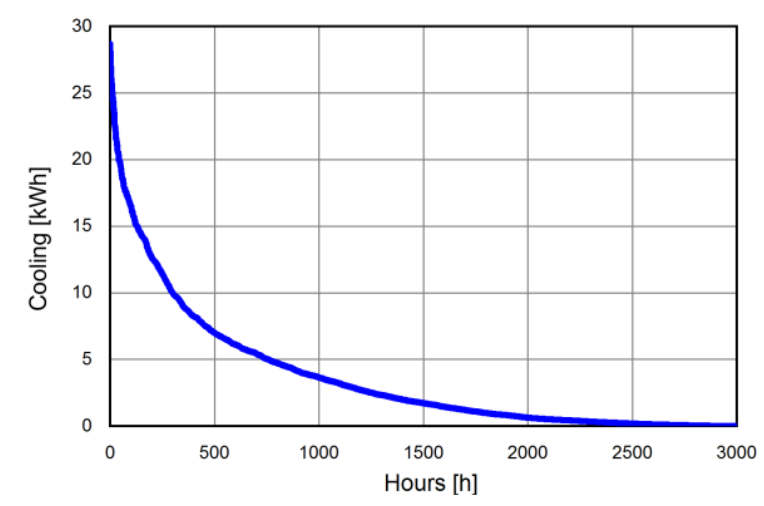

Fig. 9. Frequency Cooling energy demand across all classrooms only in the annex

The energy requirement with active sensitive cooling to maintain thermal comfort is $10,630 \mathrm{kWh} / \mathrm{a}$ with a peak heat load of $27,8 \mathrm{~kW}$, and an $95 \%$ quantile heat load of $15 \mathrm{~kW}$. Latent cooling was not evaluated in this study. The relative humidity of the inner air rises to an average value of about $56 \%$ with maximum peaks of $66 \%$. This does not seem to be an issue, compared to the reference case with average $48 \%$ relative humidity of inner air. Figure 9 shows the frequency of cooling energy demand across all classrooms. The thermal comfort in each classroom is per definition at the best level.

\subsubsection{Increased night air exchange}

With this variant, a mechanically driven volume flow of $750 \mathrm{~m}^{3} / \mathrm{h}$ with an existing night ventilation concept was used in all classrooms, including those facing north. This corresponds approximately to two to three air exchanges per hour at night. The simulation shows that with this increased night air exchange the room temperature is in the comfort level for $50 \%$ of the time during summertime.

\subsubsection{Adapted ventilation concept}

The night ventilation concept has been extended or changed in this variant with the following settings:

- A supply air fan is installed in each classroom of the extension.

- Each of these supply air fans has a maximum capacity of $750 \mathrm{~m}^{3} / \mathrm{h}$ ( three air exchanges per hour). The supply air can escape to the outside through open skylights above the classroom doors and further through the skylights in the corridor and staircase, or through exhaust air openings in the classrooms.

- The night ventilation program is active until 7:45 am.

- The design temperature to which the room air temperature can be lowered at night before the fans are switched off is set to $18^{\circ} \mathrm{C}$ instead of $21^{\circ} \mathrm{C}$ in the reference case.

- The skylights in the hallway and staircase are automatically opened during the day if it is not raining

- During the day, if the outside air temperature is helpful in reducing the inside temperature to thermal comfort one air exchange per hour (about $200 \mathrm{~m}^{3} / \mathrm{h}$ ) in the classrooms is driven by the supply air fans.
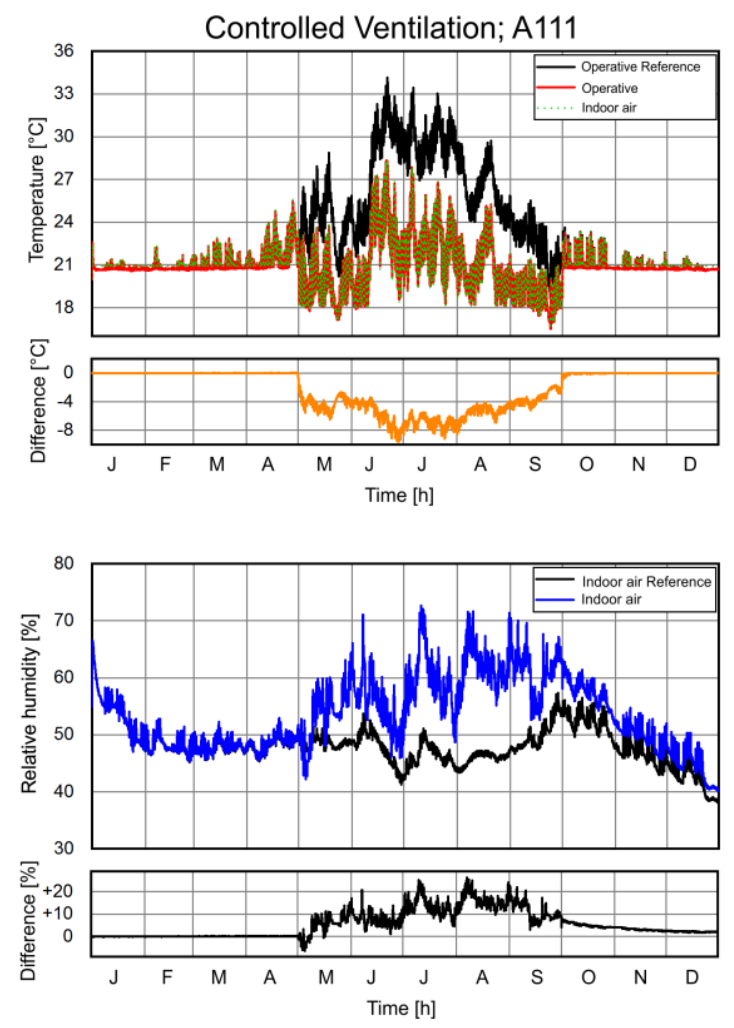

Fig. 10. Exemplary simulations results: Air temperature, operating temperature and relative humidity in classroom A111. Variation with the adapted ventilation concept compared to the reference simulation.

With these measures, the thermally comfortable time during summer is increased to $75 \%$. Fig. 10 shows that the operative temperature in the south facing room can be reduced by more than $8 \mathrm{~K}$ but the interior relative humidity increases, even more than in case of active 
cooling. This increased relative humidity was not investigated in detail in this study.

\subsection{4 g-value}

With this variant the g-value, the total energy transmittance of the glazing was reduced to 0.3 for all classrooms (south and north side). All other parameters are based on the reference simulation.

With this measure, the thermally comfortable time during summer is increased to $50 \%$.

\subsubsection{Green roof}

In this variant, the gravel fill on the flat roof is replaced by a green roof. The modeling of the green roof follows the guidelines for the calculation of extensively green roofs [13]. The green roof model used is that of Germany.

The short-wave radiation absorption coefficient is taken into account with 0.5 for medium gravel. The explicit radiation balance is taken into account for the flat roof due to the large field of view to the sky. The long-wave radiation emission is considered with 0.93 for gravel roofs. In this case the simulation with the green roof doesn't show a remarkable improvement in comfort.

\section{Summary}

Within the scope of this investigation, a simulation model of the building extension, built in 2008, of a school in Germany was created. The model was used to investigate planning variants and their influence on the indoor climate, especially to reduce overheating. The building model was checked by means of an accompanying metrological examination. For this purpose, the measured indoor climate in four classrooms and in the corridor on the upper floor of the extension was compared with the simulated indoor climate of the building model. Accepted boundary conditions in the building model were adjusted based on the findings of the measurement data. Small deviations between the measured and simulated indoor climate are still present even after the boundary conditions of the simulation have been adjusted. These are mainly due to the fact that the building operation is not completely recorded in detail. Simulated days with detailed operation states show a very good accordance. Daily courses of the calculated indoor temperature follow the measured values and it is generally assumed that the building model reflects the.

The nocturnal air exchange has a clear influence on the indoor climate. The concept initially adopted provides for south-facing supply air fans in the classrooms with electric shutters and a capacity of 750 $\mathrm{m}^{3} / \mathrm{h}$ each. This corresponds to a 3 -fold air exchange rate. First simulations with this air exchange showed a significant reduction of the room air temperature during the night towards the lower limit temperature of 20 to $21^{\circ} \mathrm{C}$. However, the measured indoor temperatures remain at a high level. A closer look reveals that with the assumption of a one-fold air exchange at night, the simulated indoor temperatures come much closer to the measured indoor temperatures. The designed ventilation rates are most likely not achieved as executed in the building, possibly due to short circuiting of air-flows or lower operation capacity of the fans than specified.

The adjusted reference simulation represents the current situation in the extension of the school and clearly shows a very frequent exceeding of comfortable indoor temperatures. Measures were examined on this reference model to reduce the uncomfortably high interior temperatures.

Active cooling was investigated in a first variant to estimate the cooling energy required if active sensible cooling was available. A total of about $10 \mathrm{kWh} /\left(\mathrm{m}^{2} \mathrm{a}\right)$ is required for all classrooms in the extension. The maximum peak load is $27,8 \mathrm{~kW}$.

In the following, three variants for improving thermal comfort without active cooling were investigated. These variants can be implemented by optimizing the existing technology or with little effort:

With variant 2 , a mechanically driven air volume flow of $750 \mathrm{~m}^{3} / \mathrm{h}$ for night ventilation was applied in all classrooms of the school extension, i.e. also in the northfacing classrooms. This corresponds to the maximum capacity specified in the existing ventilation concept, but which is not used in current operation. The adapted night ventilation can increase the thermal comfort during the periods of use: In the average value over all classrooms, a comfortable indoor climate now prevails there during $78.7 \%$ of the times-of-use (reference variant: $66.6 \%$ ) and especially in summer $54 \%$ instead of $21.4 \%$ of the reference simulation.

Version 3 builds on version 2. In addition, the control concept is adapted here: The minimum control temperature is reduced from $21{ }^{\circ} \mathrm{C}$ to $18{ }^{\circ} \mathrm{C}$. Furthermore, a daytime air exchange (one-fold air exchange, approx. $200 \mathrm{~m}^{3} / \mathrm{h}$ ) is also taken into account, whenever the outside temperature is helpful to reduce the inside temperature. As a result, the operative temperature was within the thermally comfortable range for $87.6 \%$ of the time of use. In comparison to the reference or variant 2 , however, it is not only too warm, but also too cold in about one third of the thermally uncomfortable usage time, due to the night-time reduction to $18^{\circ} \mathrm{C}$.

In addition to variants 2 and 3 , which mainly investigated whether the heat that heats up the classrooms during the day can be dissipated at night, variant 4 investigates the effect of reduced heat input via the windows. The g-value of the classroom glazing was reduced to 0.3 . With this measure, the operative temperature is lowered and remains in the thermally comfortable range for $82.3 \%$ of the time of use. As variants 2 and 3 differ from variant 4 in terms of methodology (dissipation of heat by night ventilation compared to the reduction of heat by permanent coating of the glazing), they have only a minor influence on each other and, even in combination, contribute to a more comfortable indoor climate by reducing the room temperature. 
Variant 5 represents the green roof variant. The gravel on the flat roof is replaced by generic substrate. The underlying insulation remains unchanged. This variant does not result in a significant improvement of the indoor climate or a reduction of the operative temperature, as the decisive heat input takes place via the façade.

With the knowledge gained from the measurement data, the comparison of the measurement data with the building simulation and the examined simulation variants, the following is recommended: The night ventilation concept should be adapted during operation. In addition, the solar heat input should be reduced. This can be achieved by reducing the overall energy transmittance of the classroom glazing, for example by using appropriate solar control films.

The research shows that overheating issues in nonmechanically cooled schools in central Europe can occur despite designs meeting heat protection standards. The investigated case shows that cross-checking design with operational performance for individual parameters (already during building commissioning) can reduce uncertainty, while multiple parameters do need to be taken into account for overall performance assessment. Hygrothermal building simulation can successfully be applied to investigate the impact of individual parameters and their interaction on classroom overheating. While a significant amount of uncertainty mainly caused by building use and operation remains solution strategies to mitigate overheating issues can be developed.

\section{References}

1. Künzel, H.M. 1994. Simultaneous Heat and Moisture Transport in Building Components. Dissertation. University of Stuttgart, Download: www.building-physics.com

2. Antretter F., Sauer F., Schöpfer T., Holm A. 2011. Validation of a hygrothermal whole building simulation software. Proceedings of Building Simulation 2011: 12th Conference of International Building Performance Simulation Association, Sydney, Australia

3. Pazold, M. and Antretter, F. 2013. Hygrothermische Gebäudesimulation mit MultizonenGebäudedurchströmungsmodell. Bauphysik 35 (2): 86-92.

4. DWD (2017): Ortsgenaue Testreferenzjahre von Deutschland für mittlere, extreme und zukünftige Witterungsverhältnisse. Herausgegeben von Deutscher Wetterdienst (DWD) und Bundesamt für Bauwesen und Raumordnung (BBR). Online verfügbar

https://www.dwd.de/DE/leistungen/testreferenzjahre testreferenzjahre.html

5. DWD Climate Data Center (CDC): Aktuelle stündliche Stationsmessungen der Lufttemperatur und Luftfeuchte für Deutschland, Qualitätskontrolle noch nicht vollständig durchlaufen, Version recent, abgerufen am 7.11.2018

6. DWD Climate Data Center (CDC): Stündliche Stationsmessungen der Solarstrahlung (global/diffus) und der atmosphärischen Gegenstrahlung für Deutschland, Version recent, abgerufen am 7.11.2018

7. DIN EN ISO 13370. Wärmetechnisches Verhalten von Gebäuden - Wärmeübertragung über das Erdreich - Berechnungsverfahren (Juni 2005).

8. DIN EN 15251. Eingangsparameter für das Raumklima zur Auslegung und Bewertung der Energieeffizienz von Gebäuden - Raumluftqualität, Temperatur, Licht und Akustik (Dezember 2012)

9. DIN EN ISO 7730. Ergonomie der thermischen Umgebung - Analytische Bestimmung und Interpretation der thermischen Behaglichkeit durch Berechnung des PMV- und des PPD-Indexes und Kriterien der lokalen thermischen Behaglichkeit (ISO 7730:2005); Deutsche Fassung EN ISO 7730:2005

10. VDI 2078. Berechnung der thermischen Lasten und Raumtemperaturen (Auslegung Kühllast und Jahressimulation (Juni 2015)

11. VDI 4300 Blatt 7:2001-07. Messen von Innenraumluftverunreinigungen - Bestimmung der Luftwechselzahl in Innenräumen

12. DIN 4108-2 Wärmeschutz und Energie-Einsparung in Gebäuden (February 2013)

13. Leitfaden zur Berechnung von extensiv begrünten Dächern, WUFI ${ }^{\circledR}$, Stand: November 2017. www.wufi.de 